\title{
Umbelliferone exhibits anticancer activity via the induction of apoptosis and cell cycle arrest in HepG2 hepatocellular carcinoma cells
}

\author{
SHI-MIN YU, DONG-HUI HU and JIAN-JUN ZHANG \\ Department of Infective Disease, Zhongshan Hospital of Hubei, Wuhan, Hubei 430033, P.R. China
}

Received May 4, 2014; Accepted February 11, 2015

DOI: $10.3892 / \mathrm{mmr} .2015 .3797$

\begin{abstract}
Hepatocellular carcinoma (HCC) is a highly malignant tumor, associated with poor patient prognoses, and high rates of morbidity and mortality. To date, the therapeutic strategies available for the treatment of HCC remain limited. The present study aimed to elucidate the anticancer activity of umbelliferone, a naturally occurring coumarin derivative isolated from Ferula communis, against the HepG2 HCC cell line. A 3-(4,5-dimthylthaizol-2-yl)-2,5, diphenyltetrazolium bromide assay was used to evaluate cell viability following umbelliferone treatment, and the effects of umbelliferone on cell cycle progression and apoptosis were evaluated using flow cytometry. The presence of morphological features characteristic of apoptosis, including cell shrinkage, membrane blebbing, nuclear condensation and apoptotic body formation, were evaluated in HepG2 cells following umbelliferone treatment. Cell cycle analysis conducted via propidium iodide (PI) staining indicated that umbelliferone treatment induced cell cycle arrest at $\mathrm{S}$ phase in HepG2 cells. Analysis with Annexin V and PI staining revealed that umbelliferone induced apoptotic events in HepG2 cells in a concentration-dependant manner (0-50 $\mu \mathrm{M})$. Umbelliferone also induced dose-dependant DNA fragmentation. In conclusion, umbelliferone was found to exhibit significant anticancer effects via the induction of apoptosis, cell cycle arrest and DNA fragmentation in HepG2 cancer cells.
\end{abstract}

\section{Introduction}

Malignant cancers are the second leading cause of mortality, and within this group, hepatocellular carcinoma (HCC) is the most highly malignant tumor, associated with poor patient prognoses and high rates of morbidity and mortality (1).

Correspondence to: Dr Jian-Jun Zhang, Department of Infective Disease, Zhongshan Hospital of Hubei, 26 Zhongshan Road, Wuhan, Hubei 430033, P.R. China

E-mail: jianjunzhang871@gmail.com

Key words: umbelliferone, hepatocellular carcinoma, apoptosis, cell cycle
There is an increasing incidence of HCC in China, where it is responsible for $90 \%$ of primary liver cancer cases, and represents the second most common cause of mortality. However, the therapeutic strategies available for the treatment of HCC have remained limited (2-4). Therefore the development of novel and improved anticancer agents, particularly those of natural product origin, is urgently required. Plants represent a source of numerous phytochemical compounds and secondary metabolites that have a major role in conferring their clinical properties. Almost $60 \%$ of the drugs used at present are derived from naturally occurring compounds, plants therefore represent a significant source of potential anticancer agents (5). To date, the use of medicinal plants in the treatment of cancer has been steadily increasing, due to their relative availability, affordability and reduced side effects, in comparison to those of commercially available chemotherapeutic agents $(6,7)$. In light of the continued requirement for effective anticancer drugs, medicinal and aromatic plants may present a source of novel agents, rich in terms of variety and mechanism of action $(6,7)$.

The development of HCC is preceded by the occurrence of hepatocellular damage caused by reactive oxygen species (ROS), and the induction of chronic inflammation associated with hepatocarcinogenesis. Various adjunctive therapies, including tumor necrosis factor with melphalan; cisplatin, epirubicin and 5-fluorouracil (5-FU); or doxorubicin, interferon- $\alpha$ and 5-FU have been used in the treatment of HCC. However, the major limitation to the use of chemotherapy to treat $\mathrm{HCC}$ is the cancer resistance mechanism, which occurs as a result of upregulation of multi-drug resistance protein (MDR) and a decrease in the expression levels of apoptotic proteins. For these reasons, more effective methods of chemotherapy are required in order to control cancer and apoptosis induction and facilitate successful cancer treatment (8-11). The induction of apoptosis in cancer cells is considered an effective strategy for the elimination of targeted cancerous cells. There are two major pathways that trigger apoptotic signaling, the mitochondria-dependent pathway and death receptor-dependent pathway.

In light of the limited therapeutic approaches currently available for the treatment of HCC, the present study aimed to evaluate the anticancer activity of the coumarin derivative, umbelliferone. The effects of umbelliferone on the cell cycle, apoptosis and DNA fragmentation were also evaluated in 
order to elucidate its mechanism of action. To the best of our knowledge, the present study constitutes the first such investigation regarding umbelliferone.

\section{Materials and methods}

Experimental procedure. Umbelliferone (2) was isolated from the dried shoot of Ferula communis (collected between July and August 2014; Jiuzhaigou, Chengdu, China). Briefly, the dried, well-chopped Ferula communis shoot material $(5 \mathrm{~kg})$ was extracted using the $95 \%$ method at room temperature three times, and concentrated in vacuo using a rotary evaporator (2L R206B; Senco Technology Co., Ltd., Shanghai, China) at $45^{\circ} \mathrm{C}$ to produce the crude extract $(500 \mathrm{~g})$. The extract was then sequentially partitioned with dichloromethane and ethyl acetate. The ethyl acetate soluble fraction (200 g) was subjected to silica gel column chromatography (Thomson Instruments, Clear Brook, VA, USA), eluted with a solvent mixture of n-hexane and ethyl acetate from 9:10 to 50:50 to produce 20 fractions. Fractions 10-20 were further subjected to silica gel column chromatography eluted with n-hexane and ethyl acetate (1:4) to produce compound 1 $(45 \mathrm{mg})$. The spectroscopic data $\left({ }^{1} \mathrm{H}-\mathrm{NMR},{ }^{13} \mathrm{C}-\mathrm{NMR}\right.$ and EI-MS) (8453 UV-Vis; Agilent Technologies, Santa Clara, CA, USA) were comparable to the values presented in the literature (12).

Cell lines. The HepG2 human HCC cell line was obtained from the Shanghai Cell Biology Institute of the Chinese Academy of Sciences (Shanghai, China). The cells were maintained in RPMI-1640 (Sigma-Aldrich, St. Louis, MO, USA), supplemented with 10\% FBS (Invitrogen Life Technologies, Carlsbad, CA, USA), $100 \mathrm{U} / \mathrm{ml}$ penicillin and $100 \mu \mathrm{g} / \mathrm{ml}$ streptomycin (Sigma-Aldrich) in a humidified atmosphere containing $50 \mu \mathrm{g} / \mathrm{ml} \mathrm{CO}_{2}$ at $37^{\circ} \mathrm{C}$.

Cell viability assay. The viability of cells was evaluated by a 3-(4,5-dimthylthaizol-2-yl)-2,5, diphenyltetrazolium bromide (MTT; Aladdin Chemical Co., Shanghai, China) assay. HepG2 cells were subjected to treatment with umbelliferone at various concentrations $(1,2,5,25$ or $50 \mu \mathrm{M})$ for 12,24 or $48 \mathrm{~h}$. Following drug treatment, $20 \mu \mathrm{l}$ of $5 \mathrm{mg} / \mathrm{ml}$ MTT (pH 4.6) was added to each well and incubated for a further $3 \mathrm{~h}$. Subsequently, the supernatant was removed and $100 \mu 1 /$ well dimethyl sulfoxide (Sigma-Aldrich) was added and agitated for $10 \mathrm{~min}$. The absorbance at $570 \mathrm{~nm}$ was measured with a microplate reader (Bio-Rad Laboratories, Inc., Hercules, CA, USA), using wells containing no cells as blank controls. Three independent experiments were performed. The half-maximal inhibitory concentration values $\left(\mathrm{IC}_{50}\right)$ were obtained from the MTT viability curves using GraphPad Prism 4.0 (GraphPad, La Jolla, CA, USA).

Evaluation of cell morphology following drug treatment. HepG2 cells were plated in six-well plates (Guangzhou Jet Biofil, Guangzhou, China) at a density of $1 \times 10^{6} \mathrm{cell} / \mathrm{s} / \mathrm{ml}$ and then cultured for $24 \mathrm{~h}$ to facilitate total attachment to the surface of the plates. Subsequently, the cells were subjected to treatment with various concentrations of umbelliferone $(0$, 5,25 or $50 \mu \mathrm{M}$ ) for $24 \mathrm{~h}$. Following drug treatment, culture plates were examined with an inverted light microscope (Eclipse Ti;Nikon Corp., Tokyo, Japan) and images were captured.

Another group of cells were analyzed with a staining method using acridine orange $(\mathrm{AO})$ and ethidium bromide (EB) (Sigma-Aldrich), following incubation. HepG2 cells were treated with various concentrations of umbelliferone $(0$, 5,25 or $50 \mu \mathrm{M}$ ) for $24 \mathrm{~h}$. Subsequently, cells on coverslips were collected, washed twice with phosphate-buffered saline (PBS), stained with $\mathrm{AO} / \mathrm{EB}$ solution (each $50 \mu \mathrm{g} / \mathrm{ml}$ ), and examined and photographed using a fluorescence microscope (Eclipse Ti; Nikon Corp.).

Cell cycle analysis. The cell cycle was analyzed by FACScan flow cytometry (FACSCalibur; BD Biosciences, San Jose, CA, USA) at a wavelength of $488 \mathrm{~nm}$. Briefly, HepG2 cells $\left(1 \times 10^{6}\right.$ cells) were treated with various concentrations of umbelliferone $(0,5,25$ or $50 \mu \mathrm{M})$ for $48 \mathrm{~h}$. Subsequently, cells were collected, washed with ice-cold PBS, fixed with $70 \%$ alcohol at $4^{\circ} \mathrm{C}$ for $12 \mathrm{~h}$ and stained with propidium iodide (PI) in the presence of 1\% RNase A (Invitrogen Life Technologies) at $37^{\circ} \mathrm{C}$ for $20 \mathrm{~min}$ prior to flow cytometric analysis.

Cell apoptosis detection by flow cytometry. An Apoptosis Detection kit (Multi Sciences, Shanghai, China) was used to detect cell apoptosis, according to the manufacturer's instructions. Briefly, HepG2 cells were treated with various concentrations of umbelliferone at $(0,5,25$ or $50 \mu \mathrm{M}$ ) for $48 \mathrm{~h}$. Cells were subsequently collected, washed with Annexin-binding buffer and stained with Annexin V-fluorescein isothiocyanate (FITC; Invitrogen Life Technologies) and PI for 15 min, prior to flow cytometric analysis using a FACScan Flow Cytometer (BD Biosciences).

DNA fragmentation assay. HepG2 cells were seeded in a $100-\mathrm{mm}$ cell culture dish $\left(2 \times 10^{6}\right)$ for $24 \mathrm{~h}$, and treated with 5,25 or $25 \mu \mathrm{m}$ umbelliferone for $72 \mathrm{~h}$. The untreated control and treated cells were harvested and washed with PBS, and the pellets were lysed with a $200 \mu 1$ DNA lysis buffer (1\% NP-40, $10 \mathrm{mM}$ EDTA, $50 \mathrm{mM}$ Tris- $\mathrm{HCl}$ ) for $20 \mathrm{~min}$. Following centrifugation at $336 \mathrm{x}$ g for $10 \mathrm{~min}$, the supernatants were diluted into an equal volume of $1.5 \%$ SDS, incubated with $10 \mathrm{mg} / \mathrm{ml} \mathrm{RNase}$ A at $50^{\circ} \mathrm{C}$ for $2 \mathrm{~h}$ and digested with $1.5 \mathrm{mg} / \mathrm{ml}$ proteinase K (Sigma-Aldrich) for $2 \mathrm{~h}$ at $30^{\circ} \mathrm{C}$. Following the addition of 0.5 volumes of $10 \mathrm{M}$ ammonium acetate, the DNA was precipitated with 2.5 volumes of cold ethanol and collected by centrifugation at $1,680 \mathrm{x} g$ for $30 \mathrm{~min}$. Samples were subsequently dissolved in gel loading buffer, separated by electrophoresis in $1 \%$ agarose gel and visualized under UV light following ethidium bromide staining.

Statistical analysis. All the data were analyzed using analysis of variance, followed by Dunnett's test for pair-wise comparison. The analysis of variance was performed using Microsoft Excel (Microsoft Corporation, Redmond, WA, USA) and Dunnett's test was performed using GraphPad Prism 4.0. Values are presented as the mean \pm standard deviation. $\mathrm{P}<0.05$ was considered to indicate a statistically significant difference. 


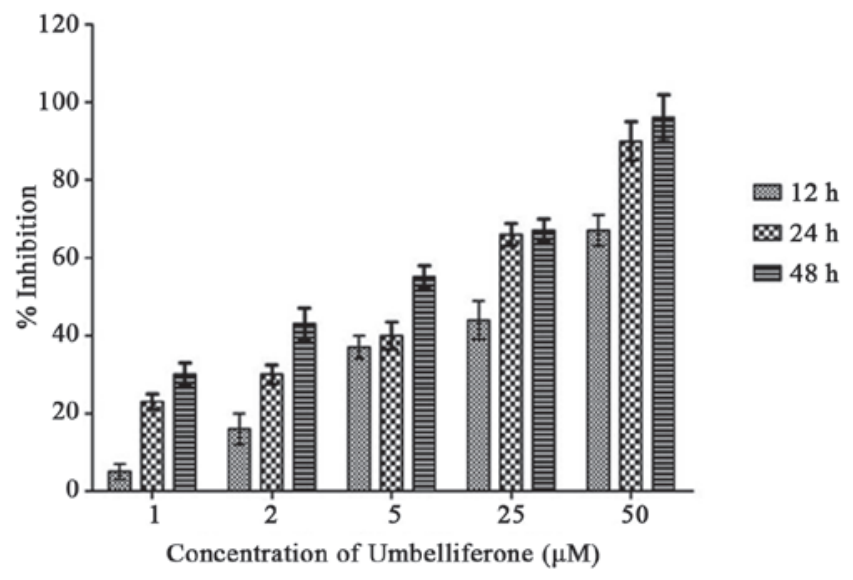

Figure 1. Cytotoxic effect of umbelliferone on HepG2 cells determined via 3-(4,5-dimthylthaizol-2-yl)-2,5, diphenyltetrazolium bromide assay. HepG2 cells were treated with umbelliferone $(1,2,5,25$ or $50 \mu \mathrm{M})$ for 12,24 or $48 \mathrm{~h}$. The $\mathrm{IC}_{50}$ values were obtained from MTT viability curves using GraphPad Prism 4.0. Data is presented as the mean \pm standard deviation.

\section{Results}

Cytotoxic effect of umbelliferone against HepG2 cells. HepG2 cells were treated with 1,2, 5, 25 or $50 \mu \mathrm{M}$ umbelliferone for 12, 24 and $48 \mathrm{~h}$, prior to the evaluation of cell viability using an MTT assay. As indicated in Fig. 1, umbelliferone induced a dose- and time-dependent reduction in cell viability. The extent of growth inhibition of various concentrations of umbelliferone on HCC cells was determined as the percentage of viable treated cells compared with the percentage of viable cells of untreated controls.

Umbelliferone induces alterations in cell morphology of HepG2 cancer cells. Malignant cells have developed multiple mechanisms to facilitate their evasion of apoptosis, the induction of apoptosis in cancer cells has been suggested to be a potentially significant strategy useful in cancer therapy and prevention (13). Apoptosis is a tightly regulated biochemical process, which is activated in order to eliminate injured or abnormal cells in multicellular organisms (14). In order to determine whether cell death induced by umbelliferone is mediated via apoptosis, HepG2 cells were treated with various concentrations of umbelliferone $(0,5,25$ or $50 \mu \mathrm{M}$ ) for $24 \mathrm{~h}$. The cells were subsequently examined under an inverted light fluorescence microscope in order to detect the presence of the characteristic morphological features of apoptosis. As exhibited in Fig. 2, 5 and $25 \mu \mathrm{M}$ umbelliferone treatment resulted in the appearance of cell shrinkage and membrane blebbing, when compared with the morphology of untreated cells $(0 \mu \mathrm{M})$. Following treatment with $50 \mu \mathrm{M}$ umbelliferone, almost all the HepG2 cancer cells shrank significantly and no cells with normal morphological features were detected.

Furthermore, AO and EB double-staining of the HepG2 cells was performed in order to detect cell apoptosis using a fluorescence microscope. Following AO/EB staining, viable cells ( $0 \mu \mathrm{M}$ umbelliferone; Fig. 3) exhibited large nuclei and intact membranes, which indicated that no ethidium bromide entered into the cell. However, following treatment with 5 and

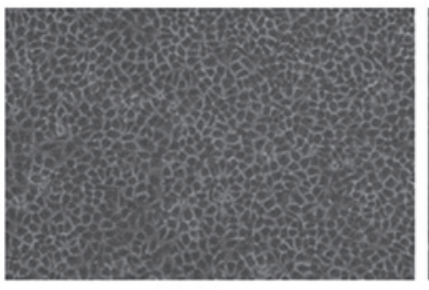

$0 \mu \mathrm{M}$

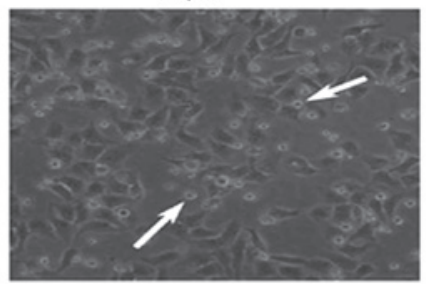

$25 \mu \mathrm{M}$

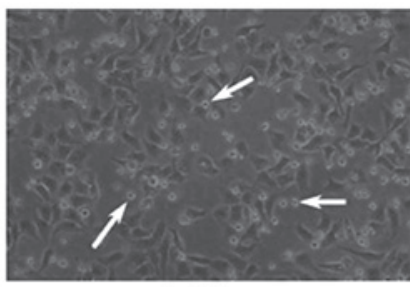

$5 \mu \mathrm{M}$

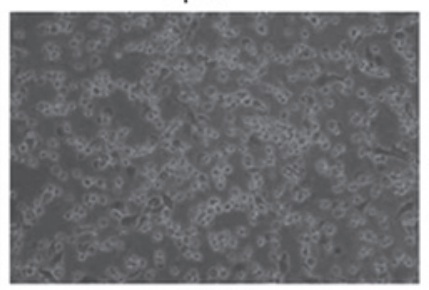

$50 \mu \mathrm{M}$
Figure 2. Umbelliferone induces morphological changes characteristic of apoptosis in HepG2cells. Morphological changes of HepG2 cells induced by $(0,5,25$ or $50 \mu \mathrm{M})$ umbelliferone treatment for $24 \mathrm{~h}$. White arrow heads indicate cell shrinkage and membrane blebbing. Magnification, x20.

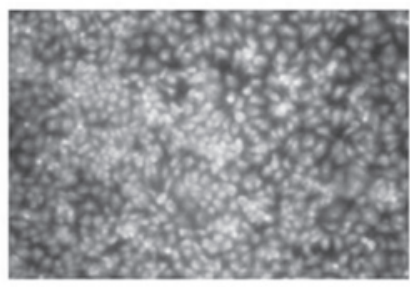

$0 \mu \mathrm{M}$

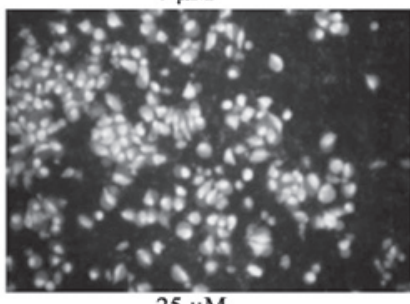

$25 \mu \mathrm{M}$

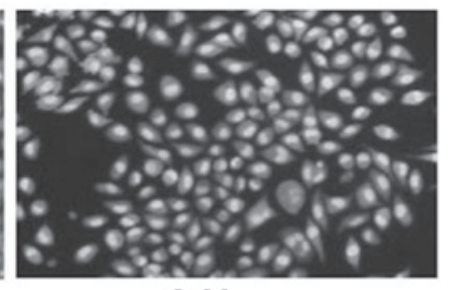

$5 \mu \mathrm{M}$

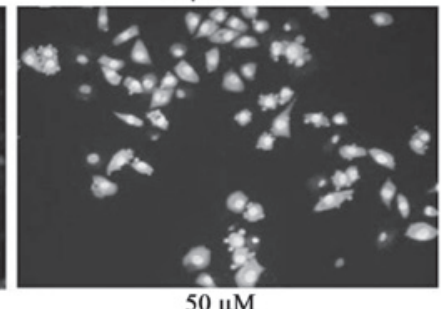

Figure 3. Acridine orange/ethidium bromide staining of HepG2 cells placed on coverslips and treated with various concentrations of umbelliferone $(0,5,25$ or $50 \mu \mathrm{M})$. Magnification, $\mathrm{x} 20$.

$25 \mu \mathrm{M}$ umbelliferone, the number of cells exhibiting large nuclei was significantly reduced (Fig. 3). In addition, following treatment with umbelliferone at a concentration of $50 \mu \mathrm{M}$, almost all cells showed signs of nuclear condensation and apoptotic body formation.

Umbelliferone induces cell cycle arrest in HepG2 cells. Flow cytometric analysis using PI as a staining agent was performed following treatment with umbelliferone at various concentrations $(0,5,25$, and $50 \mu \mathrm{M})$ for $24 \mathrm{~h}$, in order to determine whether umbelliferone induced cell cycle disturbances in HepG2 cells. As displayed in Fig. 4, following treatment with umbelliferone at 5, 25 and $50 \mu \mathrm{M}$, an increase in the proportion of cells in $\mathrm{S}$ phase $(45.0,51.3$ and $62.1 \%$, compared with $43.6 \%$ in untreated cells) and a reduction in the fraction of cells in G1 phase (42.1, 45.6 and $32.2 \%$, compared with $53.2 \%$ in the untreated cells) was observed. 

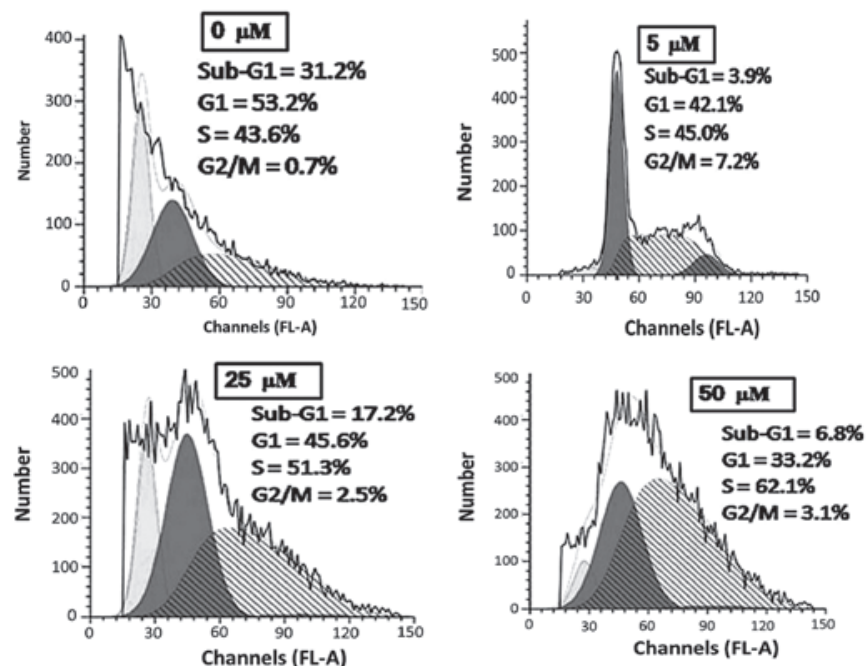

Figure 4. Umbelliferone induces cell cycle arrest in HepG2 cells. Flow cytometric analysis of HepG2 cells treated with various concentrations of umbelliferone $(0,5,25$ or $50 \mu \mathrm{M})$ for $48 \mathrm{~h}$, harvested, stained with propidium iodide and analyzed by flow cytometry. Each histogram represents the percentage of cells in sub-G1, G1, S and G2/M phases of the cell cycle.

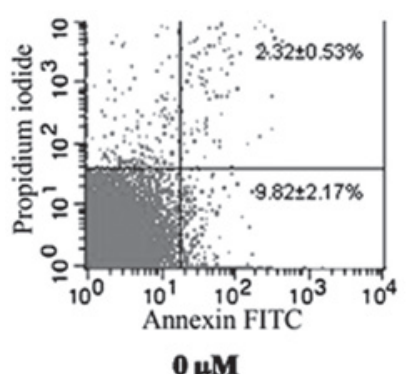

$\mathbf{0} \boldsymbol{\mu M}$

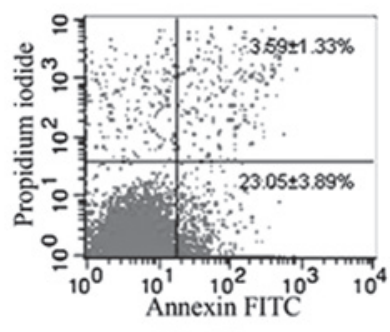

$25 \mu \mathrm{M}$
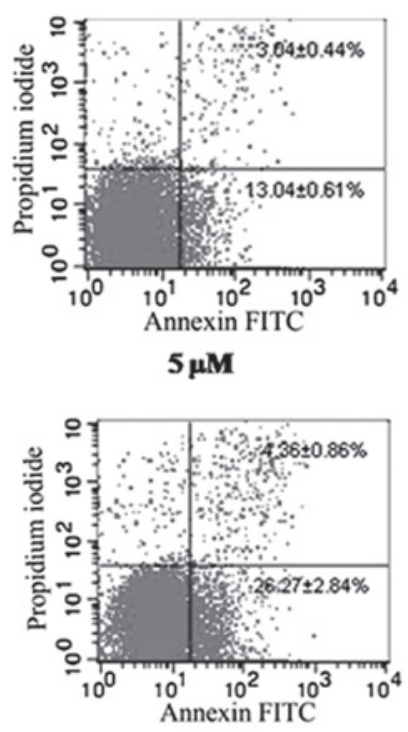

$50 \mu \mathrm{M}$
Figure 5. Umbelliferone induces apoptosis in HepG2 cells. HepG2 cells were treated with various concentrations $(0,5,25$ or $50 \mu \mathrm{M})$ of umbelliferone for $48 \mathrm{~h}$, then harvested, stained with Annexin V/PI and analyzed by flow cytometry. Treatment with umbelliferone resulted in an increase in Annexin V and PI staining that indicated the occurrence of mainly early apoptotic events. PI, proidium iodide; FITC, fluorescein isothiocyanate.

Umbelliferone induces death in HepG2 cells via apoptosis. In the current study, staining was performed using Annexin V/FITC, a protein that has a high affinity for phosphatidyl serine (PS) and exhibits fluorescence. PS is a phospholipid component localized on the cytoplasmic surface of the cell membrane of normal, viable cells. Following the induction of apoptosis in a cell, PS is no longer restricted to the cytosolic section of the membrane and is exposed on the cellular surface. PS translocation is therefore considered to be a biochemical marker of apoptosis. Annexin V staining detects the presence of PS and is therefore able to be used for PS

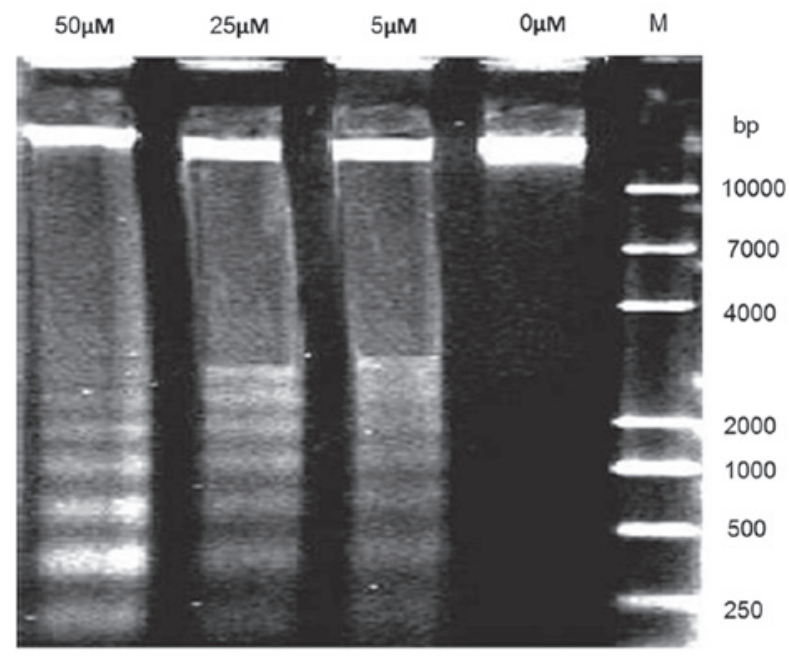

Figure 6. Umbelliferone induces DNA fragmentation in HepG2 cells. Umbelliferone treatment for $72 \mathrm{~h}$ at various concentrations $(0,5,25$ or $50 \mu \mathrm{M})$ resulted in DNA fragmentation in HepG2 cells. Apoptotic DNA fragments were confirmed by staining with ethidium bromide in $1 \%$ agarose gel. M, marker

expression analysis (14). Once cells are stained with Annexin V and PI, the Annexin V/PI stain is only able to enter the cell when the plasma membrane is sufficiently compromised. This facilitates distinguishing cells in the early apoptotic phase (positive for PS, but negative for PI) from the late apoptotic and necrotic cells (positive for PS and PI) $(15,16)$. As shown in Fig. 5, increasing doses of umbelliferone $(0-50 \mu \mathrm{M})$ resulted in the induction of apoptotic events, particularly early apoptosis, in a dose-dependent manner.

Umbelliferone induces DNA fragmentation. Pronounced DNA fragmentation was observed in HepG2 cancer cells following treatment with 5,25 and $50 \mu \mathrm{M}$ umbelliferone, for $72 \mathrm{~h}$. However, the control cells $(0 \mu \mathrm{M})$ did not produce a clear DNA ladder (Fig. 6).

\section{Discussion}

HCC is a type of malignant cancer, associated with a high incidence and rate of mortality. The therapeutic approaches currently available for the treatment of HCC remain limited. Despite of the fact that chemotherapy is one of the most effective therapeutic approaches for HCC, the associated toxic side effects mean that it is difficult to tolerate (1). For these reasons, there is an urgent requirement for the design and development of novel therapeutic agents, which exhibit higher efficacy and induce fewer serious side effects (17). Natural product-based therapies, including the use of natural plant-derived products and traditional Chinese medicine in cancer therapies, may aid minimization of the induction of adverse side effects (18). Medicinal and aromatic plants represent a rich source of anticancer chemotherapeutic drugs, which exhibit low or no toxicity to normal cells. Increasing attention is therefore being paid to the search for novel anticancer drugs derived from natural sources (19).

Umbelliferone (2), also termed 7-hydroxycoumarin, is a wide-spread natural product of the coumarin family. 
Umbelliferone is a yellow-white crystalline solid, which occurs in numerous well-known plants, including carrots, coriander, angelica, Hydrangea macrophylla and Ferula communis. Umbelliferone is currently used in sunscreens as it is able to absorb ultraviolet light effectively at multiple wavelengths (20). It has also been reported to exhibit antinociceptive, anti-inflammatory and bronchodilator activities, and certain studies have additionally reported its analgesic activities $(21,22)$. Umbelliferone has been reported to exhibit antitumor and immunomodulatory effects against sarcoma 180 in mice, inhibiting tumor growth and increasing survival time of tumor-bearing animals (23). Kielbus et al (24) reported that umbelliferone inhibited proliferation and migration of laryngeal cancer cells in vitro. The authors reported that umbelliferone reduced viability and migration of RK33 laryngeal cancer cells in a dose-dependent manner (24). Antitumor activities of umbelliferone have also been reported against 7,12-dimethylbenz(a)anthracene-induced rat mammary carcinomas (25).

In conclusion, to the best of our knowledge, the anticancer activity of umbelliferone against HepG2 cancer cells has not previously been reported. The current study is therefore the first to investigate the cytotoxic mechanism of umbelliferone action. The results revealed that umbelliferone induced apoptosis in HepG2 cells. Therefore, umbelliferone may have the potential to be used in the management and treatment of liver cancer, provided further studies are performed to verify this role.

\section{References}

1. Filipova A, Seifrtova M, Mokry J, Dvorak J, Rezacova M, Filip S and Diaz-Garcia D: Breast cancer and cancer stem cells: A minireview. Tumori 100: 363-369, 2014.

2. Li ZF, Wang ZD, Ji YY, Zhang S, et al: Induction of apoptosis and cell cycle arrest in human HCC MHCC97H cells with Chrysanthemum indicum extract. World J Gastroenterol 15 4538-4546, 2009.

3. Lu CX, Nan KJ, Nie YL, Hai YN and Jiao M: Delisheng, a Chinese medicinal compound, exerts anti-proliferative and pro-apoptotic effects on HepG2 cells through extrinsic and intrinsic pathways. Mol Biol Rep 37: 3407-3412, 2010.

4. Roomi MW, Roomi NW, Kalinovsky T, Niedzwiecki A and Rath M: In vivo and in vitro effect of a nutrient mixture on human hepatocarcinoma cell line SK-HEP-1. Exp Oncol 32: 84-91, 2010.

5. Newman DJ: Natural products as leads to potential drugs: An old process or the new hope for drug discovery? J Med Chem 51: 2589-2599, 2008.

6. Manosroi J, Sainakham M, Manosroi W and Manosroi A: Anti-proliferative and apoptosis induction activities of extract from Thai medicinal plant recipes selected from MANOSROI II database. J Ethnopharmacol 141: 451-459, 2012.

7. Engel N, Oppermanne C, Falodunb A and Kragle U: Proliferative effects of five traditional Nigerian medicinal plant extracts on human breast and bone cancer cell lines. J Ethnopharmacol 137: 1003-1010, 2011.
8. Tanaka H, Fujita N, Sugimoto R, Urawa N, et al: Hepatic oxidative DNA damage is associated with increased risk for hepatocellular carcinoma in chronic hepatitis $\mathrm{C}$. Br J Cancer 98: 580-586, 2008

9. Park SH, Lee Y, Han SH, Kwon SY, et al: Systemic chemotherapy with doxorubicin, cisplatin and capecitabine for metastatic hepatocellular carcinoma. BMC Cancer 6: 3, 2006.

10. Chen YB, Yan ML, Gong JP, Xia RP, et al: Establishment of hepatocellular carcinoma multidrug resistant monoclone cell line HepG2/mdrl. Chinese Med J (Engl) 120: 703-707, 2007.

11. Locher C, Conforti R, Aymeric L, Ma Y, et al: Desirable cell death during anticancer chemotherapy. Ann NY Acad Sci 1209: 99-108, 2010

12. Jizhong Y and Shengqiang T: Preparative isolation and purification of two coumarins from Edgeworthia chrysantha lindl by high speed countercurrent chromatography. J Liq Chromatogr Relat Technol 29: 1307-1315, 2006.

13. Taraphdar AK, Roy M and Bhattacharya RK: Natural products as inducers of apoptosis: Implication for cancer therapy and prevention. Current Sci 80: 1387-1396, 2001.

14. Yu HY, Zhang XQ, Li X, Zeng FB and Ruan HL: 2-methoxyjuglone induces apoptosis in HepG2 human hepatocellular carcinoma cells and exhibits in vivo antitumor activity in a H22 mouse hepatocellular carcinoma model. J Nat Prod 76: 889-895, 2013.

15. Darzynkiewicz Z, Bruno S, Del Bino G, Gorczyca W, et al: Features of apoptotic cells measured by flow cytometry. Cytometry 13: 795-808, 1992.

16. Nicoletti I, Migliorati G, Pagliacci MC, Grignani F and Riccardi C: A rapid and simple method for measuring thymocyte apoptosis by propidium iodide staining and flow cytometry. J Immunol Meth 139: 271-279, 1991

17. Mukherjee AK, Basu S, Sarkar N and Ghosh AC: Advances in cancer therapy with plant based natural products. Curr Med Chem 8: 1467-1486, 2001.

18. Wang S, Penchala S, Prabhu S, Wang J and Huang Y: Molecular basis of traditional Chinese medicine in cancer chemoprevention. Curr Drug Discov Technol 7: 67-75, 2010.

19. Desai AG, Qazi GN, Ganju RK, El-Tame M, et al: Medicinal plants and cancer chemoprevention. Curr Drug Metab 9: 581-591, 2008.

20. Lorenzetti OJ, Boltralik J, Bushy E and Fortenberr B: The influence of protein vehicles on the penetrability of sunscreens. J Soc Cosmet Chem 26: 593, 1975.

21. Leal LK, Ferreira AA, Bezerra GA, Matos FJ and Viana GS: Antinociceptive, anti-inflammatory and bronchodilator activities of Brazilian medicinal plants containing coumarin: a comparative study. J Ethnopharmacol 70: 151-159, 2000.

22. Lino CS, Taveira ML, Viana GSB and Matos FJA: Analgesic and antiinflammatory activities of Justicia pectoralis Jacq and its main constituents: coumarin and umbelliferone. Phytother Res 11: 211-215, 1997.

23. Stefanova TH, Nikolova NJ, Toshkova RA and Neychev HO: Antitumor and immunomodulatory effect of coumarin and 7-hydroxycoumarin against Sarcoma 180 in mice. J Exp Ther Oncol 6: 107-115, 2007.

24. Kielbus M, Skalicka-Wozniak K, Grabarska A, Jeleniewicz W, et al: 7-substituted coumarins inhibit proliferation and migration of laryngeal cancer cells in vitro. Anticancer Res 33: 4347-4356, 2013.

25. Maucher A and von Angerer E: Antitumour activity of coumarin and 7-hydroxycoumarin against 7,12-dimethylbenz[a] anthracene-induced rat mammary carcinomas. J Cancer Res Clin Oncol 120: 502-504, 1994. 